\title{
Mathematical Model: Thermal Effects of Two Wheeler Rider's Speed in His/Her Eye
}

\author{
Gokul KC $^{1 *}$ and Dil Bahadur Gurung ${ }^{1}$ \\ ${ }^{1}$ Department of Mathematics, School of Science, Kathmandu University, Dhulikhel, Nepal \\ *Corresponding author E-mail: gokul.kc@ku.edu.np
}

\author{
Article Info \\ Keywords: Airflow forced convection, \\ Bio-heat transfer, Eyelid blinking, Tem- \\ perature distribution, Two wheeler \\ rider \\ 2010 AMS: 92B05, 80A20 \\ Received: 23 December 2018 \\ Accepted: 31 August 2019 \\ Available online: 26 December 2019
}

\begin{abstract}
High speed airflow into the cornea accelerates evaporation and heat transfer. Eyelid blinking increases with increased airflow speed into the eye. Increased blinking increases corneal temperature when drops below normal level. In cold climatic condition high speed airflow causes rapid temperature drop. Most often, eye injuries caused by cold exposure occur in individuals who try to force their eyes open in high speed wind and cold weather such as two wheeler rider. The purpose of this study is to investigate the temperature changes in two wheeler rider's cornea, considering eyelid blinking, in his/her different speed. Thus, in this paper, bio-heat transfer process is simulated using finite element method at rider's different speed in transient state cases. In still air, blinking increases corneal temperature by $2.74^{\circ} \mathrm{C}$ at normal ambient temperature $22.5^{\circ} \mathrm{C}$ than in open eye. At ambient temperature $0^{\circ} \mathrm{C}$ and rider's speed $60 \mathrm{~km} / \mathrm{hr}$, corneal temperature drops to $5.45^{\circ} \mathrm{C}$ in open eye, while blinking increases this temperature by $6.28^{\circ} \mathrm{C}$. Similarly at ambient temperature $40^{\circ} \mathrm{C}$, blinking reduces corneal temperature by $0.51^{\circ} \mathrm{C}$. Corneal temperature approaches steady state quickly at higher rider's speed.
\end{abstract}

\section{Introduction}

\subsection{Background of the study}

Dry eye condition affects millions of people, interfering with their daily living and normal activities. Actual causes associated with dry eye are multifactorial [1]. Certain environmental conditions such as high or low temperatures, low humidity and wind flow are known factors to cause dry eye. Among them, the most striking change of corneal surface temperature is brought about by air movement. High speed air into the eye causes significant decrease in lipid layer and tear stability [2]. This may destroy or make thinner the lipid layer, which increases evaporation. Increased evaporation of tear causes dry eye.The heat transfer between air molecules and cornea increases with air velocity. Since more air molecules would hit the corneal surface, high amount of heat is transferred by evaporation of water from precorneal tear film. Also with airflow, the thermal boundary layer of air between cornea and environment becomes thinner. This decreases the diffusion distance between cornea and environment, causes high heat transfer.

High air velocity causes more evaporation of water from the pre-corneal tear film and increases heat transfer by eliminating the boundary of air adjacent to tear film than in stagnant ambient air. High speed air is associated with forced convection by which significant amount of heat can be transported quickly and effectively [3]. The amount of heat transported by air through forced convection is proportional to the flow speed. The forced convection by hot/cold high speed airflow increases/decreases eye temperature. As the temperature within the eye increases/decreases, the eye will respond with more protective cooling/heating mechanism, such as more frequent blinking [4].

Blinking agitates the pre-corneal tear film secreted at body core temperature. With each blink a warm lacrimal secretion is layered across the cornea giving heat both to environment and to the cornea. The act of blinking expels and sucks alternatively a new layer of air over the surface of the pre-corneal film [5]. The ocular exposure to most of the cornea and lens is strongly affected by the blinking [6]. During blinking, the eyelid closure time is much shorter than opening; however, the convected heat of perfusing blood from vascular conjunctiva 
may contribute to anterior corneal temperature[7].

Lagendijk [8]used a finite difference method to calculate the temperature distribution in human and rabbit eyes during hyperthermia treatment. The heat transport from the sclera to the surrounding anatomy is described by a single heat transfer coefficient which includes the impact of blood flow in choroid and sclera. Flyckt et al. [9] studied the impact of choroidal blood flow by using three methods: Lagendijk model, bio-heat model and discrete vasculature model in the eye and the orbit. Scott [10] utilized finite element method to obtain the temperature profile based on heat conduction using various heat transfer coefficients given by Lagendijk. He acknowledged the deficiencies were the lack of including the effects of eyelid closure, eyelid blinking and the environmental wind flow. Shafai and vafai [11] proposed the porous media model along with natural convection to analyze the eye thermal characteristics during exposure to thermal disturbances. Sharon et al.[12] studied the heat exposure and damage to the eye lens, using finite volume and finite element method, when exposed to environmental temperature fluctuations. $\mathrm{Ng}$ and Ooi [13] presented a 2D finite element model, simulated ocular surface temperature and compared the results with the model developed by Scott. Ooi and $\mathrm{Ng}$ [14] studied the effect of aqueous humor hydrodynamics on heat transfer within human eye. The limitation they conceded was excluding the presence of eyelid on ocular surface and thermal effects of blinking. Scott [4] studied the effects of eyelid shielding by considering normal blinking rate without considering the effect of blood flow in eyelid.

Some models ([4], [15]) performed sensitivity analysis by varying the values of convection heat transfer coefficient between cornea and environment. Some authors([8], [9]) studied the convection effects of blood flow in posterior eye. However, most authors neglected the effects of eyelid blinking and forced convection due to air velocity in corneal surface, although it is significant.

\subsection{Significance of blinking in forced convection}

Blinking is regarded as the continuous interrupted eyelid closure or opening and its thermal effect will compromise between these two. Infants blink at an average rate of one or two times in a minute. The mean eye blink rate in normal individuals varies from $2-25$ blink per minute. Many factors may affect blink rate, including gender (the rate is higher in women than in men), the time of day (blinking is more frequent in the evening), the degree of concentration on visual tasks and presence of ocular discomfort or disease [16]. During a blink the act of eyelid closure occupies 0.05 seconds, the closure is maintained for 0.15 seconds and is followed by eyelid opening taking 0.2 seconds, thus the whole blink lasts approximately 0.4 seconds with mean inter blink time of 2.8 seconds in male and 4 seconds in female [5]. There are four types of temperature effects of blinking on anterior corneal surface:heating/cooling due to spread of warm tears and lipids across the surface of cornea, heating/cooling caused by the movement of the eyelid, heating/cooling via convection, radiation and tear evaporation and heating/cooling by the formation of new layer of air over the surface of cornea [17].

The use of two wheelers in developing countries has been increasing rapidly. While driving, two wheeler rider wears helmet with visor. Visor prevents driver's eye from dust, smoke, foreign body, and hot/cold wind flow. In several cases, the driver used to open their visor. Some of the cases are:

1. When the environmental temperature is very low than normal, the water vapor due to respiration covers hole area of visor's inner part causes poor vision

2. When raining, the rain water drops hits the visor surface continuously causes blurred vision

3. At night, the refraction of light into the visor by anti-vehicles light or street lights causes poor vision.

In the above cases, the airflow caused by riders speed directly interacts with riders' cornea or eyelid skin surface, cause forced convection heat transfer.

In outdoor condition, the wind accelerates the drop in temperature of the ocular surface below normal level. Most often, eye injuries caused by cold exposure occur in individuals who try to force their eyes open in high wind or cold weather such as in the case of two-wheeler rider. The normal human corneal temperature ranges from $32-34^{\circ} C[5,7,18]$. However, in cold conditions and high-speed wind flow the temperature of human eyelids and the corneal surface drops well below normal level. If the ocular surface and the eyelid temperature drop below $30^{\circ} \mathrm{C}$ (a distinctive possibility in cold weather, especially in combination with wind), the chances are that:

1. Meibomian gland would impede its normal delivery of meibum [19]

2. The blood flow rate in eyelid decreases due to vasoconstriction [20]

3. Uniform distribution of lipid layer is broken that causes greater evaporation [21]

4. Tear secretion increases to maintain eye temperature normal that causes excess tearing [5]

5. Blink frequency increases to maintain normal eye temperature where possible [22]

6. Eye pain, blurred vision starts

These events may limit the protective effect of lipid layer, tear layer, eyelid and meibomian gland. Thus long time exposure of eye in cold weather in combination with wind may cause dry eye, refractive errors and severe sensitivity to light.Thus, it is worth investigating the temperature changes and its effects in the eye during eyelid opening, closure and blinking with appropriate forced convection coefficient. In this study eyelid is considered as heating/cooling source of anterior cornea and model as a part of ocular component. The effect of wind flow in temperature distribution specially the temperature drop in two wheeler riders eye surface is modeled using appropriate physical and physiological values at rider's different speed. The purpose of this study are 1) to develop computational approach to predict temperature distribution and 2) to demonstrate the impact of high speed wind flow on temperature, which may be regarded to cause several eye injuries. The potential users of this model would be the visor industries, general public(two wheeler rider) and biological and medical persons.

\section{Model formulation}

\subsection{Discretization}

A schematic diagram of two dimensional human eye is presented in figure 2.1. The human eye is considered to have 8 major components: cornea, aqueous humor, lens, vitreous humor, ciliary body, iris, retina, sclera. The diameter of eye along pupillary axis ( $\mathrm{x}$-axis) is $25.10 \mathrm{~mm}$ and along vertical axis is (y-axis) is $23 \mathrm{~mm}$. 


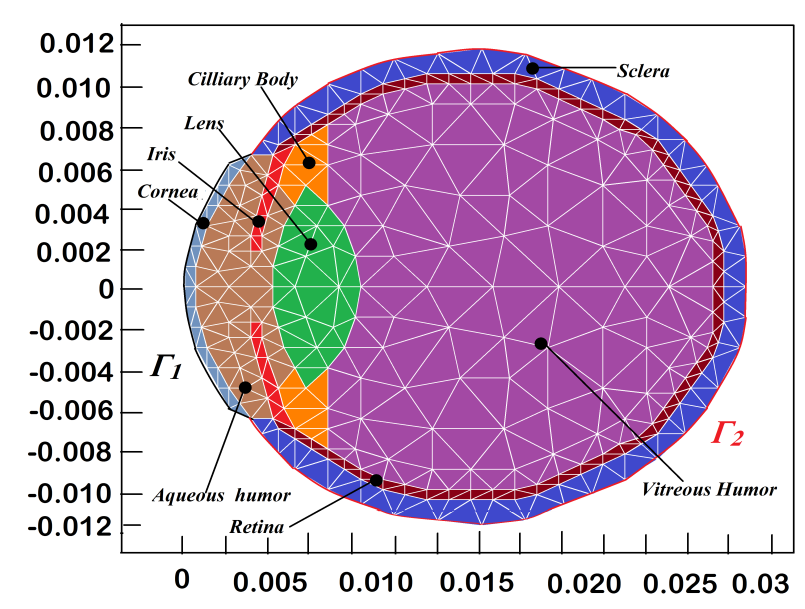

Figure 2.1: Finite element discretization of human eye tissues in two dimension.

The human eye when eyelid is opened is considered to have 11 major components: skin, orbicularis oculi, tarsal plate, cornea, aqueous humor, lens, vitreous humor, ciliary body, iris, retina and sclera. The diameter of eye along pupillary axis(x-axis) is $29.35 \mathrm{~mm}$ and along vertical axis is (y-axis) is $23 \mathrm{~mm}$. Initially, the open eye with eyelid is divided into 635 triangular elements with 350 nodes. The skin, orbicularis oculi, tarsal plate, cornea, aqueous humor, iris, ciliary body, lens, vitreous humor, retina, and sclera are divided into 14,51,18,26,72,20,16,32,180,110 and 96 triangular elements as shown on figure 2.2 .

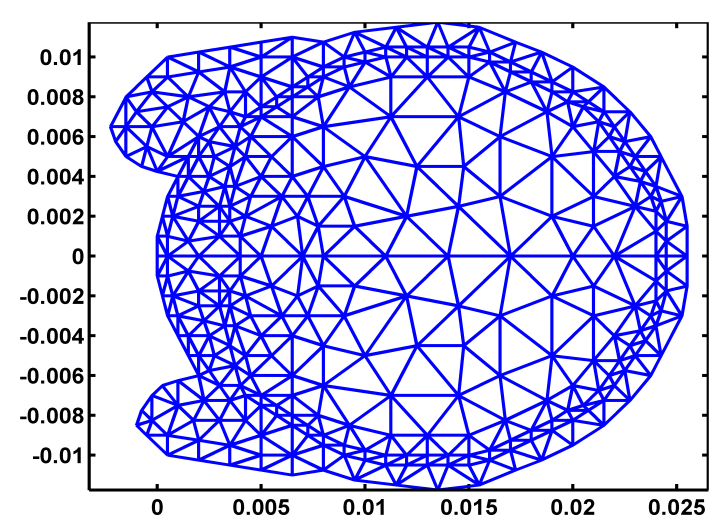

Figure 2.2: Two dimensional eye when eyelid is open

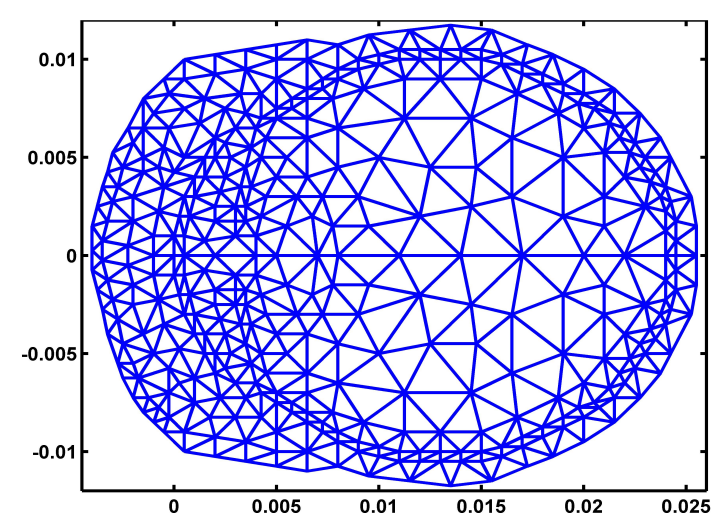

Figure 2.3: Two dimensional eye when eyelid is closed

Similarly, the human eye when eyelid is closed is considered to have 11 major components: skin, orbicularis oculi, tarsal plate, cornea, aqueous humor, lens, vitreous humor, ciliary body, iris, retina and sclera. The diameter of eye along pupillary axis(x-axis) is $29.35 \mathrm{~mm}$ and along vertical axis is (y-axis) is $23 \mathrm{~mm}$. The closed eye is divided into 730 triangular elements with 395 nodes. The skin, orbicularis oculi, tarsal plate, cornea, aqueous humor, iris, ciliary body, lens, vitreous humor, retina, and sclera are divided into 44,100,34,26,72,20,16,32, 180,110 and 96 triangular elements as shown on figure 2.3.

\subsection{Governing equation and boundary condition}

The governing differential equation representing the bio-heat transfer in the human eye can be written by the well known Pennes equation addressing the effect of blood perfusion and metabolism [23] is given by:

$$
\rho c \frac{\partial T}{\partial t}=\nabla \cdot(K \nabla T)+\omega \rho_{b} c_{b}\left(T_{b}-T\right)+Q_{m}+Q
$$

where, $\rho_{b}=$ blood density $\left(\mathrm{Kgm}^{-3}\right), c_{b}=$ blood specific heat $\left(\mathrm{JKg}^{-1^{o}} \mathrm{C}^{-1}\right), k=$ tissue thermal conductivity $\left(\mathrm{Wm}^{-1^{o}} \mathrm{C}^{-1}\right), \omega=$ volumetric blood perfusion rate per unit volume $\left(s^{-1}\right), T_{b}=$ blood temperature $\left({ }^{\circ} \mathrm{C}\right), T=$ tissue temperature $\left({ }^{\circ} \mathrm{C}\right), Q_{m}=$ heat generation due to metabolism $\left(W m^{-3}\right)$ and $\mathrm{Q}=$ heat generation due to external heat source $\left(W m^{-3}\right)$.

Boundary conditions for the system can be defined as follows:

1. On the outer surface of the sclera, the heat flows run into the eye with the complicated network of ophthalmic vessels which are located inside the choroidal layer acting as a heating source to the sclera. This heat exchange between the eye and the surrounding is modeled using the following convection boundary condition:

$$
\Gamma_{2}:-k_{s} \frac{\partial T}{\partial \eta}=h_{b}\left(T-T_{b}\right)
$$


where $\eta$ is the normal direction to the surface boundary, $k_{s}$ is the thermal conductivity of sclera, $h_{b}$ is the heat transfer coefficient between blood and eye $\left(\mathrm{Wm}^{-2}{ }^{\circ} \mathrm{C}^{-1}\right)$, and $T_{b}$ is blood temperature $\left({ }^{\circ} \mathrm{C}\right)$.

2. Since outer surface of the eye (cornea or skin) is exposed to the environment, the heat loss caused via convection, radiation, and evaporation. This loss is modeled using the following boundary condition :

$$
\Gamma_{1}:-k_{c} \frac{\partial T}{\partial \eta}=h_{a}\left(T-T_{a}\right)+\sigma \varepsilon\left(T^{4}-T_{a}^{4}\right)+E
$$

where $h_{a}=\left\{\begin{array}{ll}h_{c}, & \text { When eyelid is opened } \\ h_{s}, & \text { When eyelid is closed }\end{array}, h_{c}\right.$ represents heat transfer coefficient between environment and cornea and $h_{s}$ represents

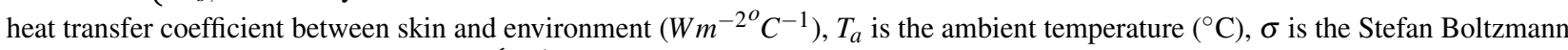
constant $\left(5.67 \times 10^{-8} \mathrm{Wm}^{-2^{o}} \mathrm{C}^{-4}\right), \varepsilon=\left\{\begin{array}{ll}\varepsilon^{\prime}, & \text { emissivity of cornea } \\ \varepsilon, & \text { emissivity of skin }\end{array}\right.$, and

$E=\left\{\begin{array}{ll}E^{\prime}, & \text { When eyelid is opened } \\ E, & \text { When eyelid is closed }\end{array}, E^{\prime}\right.$ is evaporative heat loss $\left(\mathrm{Wm}^{-2}\right)$ between cornea and environment and $\mathrm{E}$ is evaporative heat $\operatorname{loss}\left(W^{-2}\right)$ between eyelid skin surface and environment.

The inner body core temperature $T_{C}$ is assumed to be $37^{\circ} \mathrm{C}$. Therefore, the initial boundary condition is

$$
T_{c}=37^{\circ} \mathrm{C}
$$

\subsection{Forced convection}

Forced convection heat transfer from cornea or eyelid skin surface results from an airstream perturbing the insulating boundary layer of air clinging to the surface. The fundamental non-dimensional quantities describing forced convection are Nusselt number(Nu), Prandtl number(Pr) and Reynolds number(Re). These three dimensionless groups are related together with the following equation [24]

$$
N u=C R e^{n} \operatorname{Pr}^{m}
$$

where $\mathrm{C}, \mathrm{m}$ and $\mathrm{n}$ are constants to be determined from experimental data. The three quantities $\mathrm{Nu}, \mathrm{Re}$, and Pr further expressed as follows

$$
\begin{aligned}
N u & =\frac{h_{a} d}{k_{f}} \\
P r & =\frac{v_{f}}{\alpha} \\
R e & =\frac{u_{a} d}{v_{f}}
\end{aligned}
$$

where $h_{a}$ is convective heat transfer coefficient $\left(w m^{-2}{ }^{\circ} C^{-1}\right), k_{f}$ is the thermal conductivity of the air $\left(w m^{-1}{ }^{\circ} C^{-1}\right), d$ is the diameter of cornea $(m), u_{a}$ is ambient air speed $\left(m s^{-1}\right), v_{f}$ is kinematic viscosity $\left(m^{2} s^{-1}\right) 4$ and $\alpha$ is thermal diffusivity $\left(m^{2} s^{-1}\right)$.

The correlations of the experimental data of Hilpert for gases indicate that the average heat transfer coefficients may be calculated with the following equation

$$
N u=C R e^{n} \operatorname{Pr}^{\frac{1}{3}}
$$

where the constants $\mathrm{C}$ and $\mathrm{n}$ are tabulated in table 2 [25]. Properties for use with equation(2.9) are evaluated at the film temperature as

\begin{tabular}{|c|c|c|}
\hline $\mathrm{Re}$ & $\mathrm{C}$ & $\mathrm{n}$ \\
\hline $0.4-4$ & 0.989 & 0.330 \\
$4-40$ & 0.911 & 0.385 \\
$40-4000$ & 0.683 & 0.466 \\
$4000-40000$ & 0.193 & 0.618 \\
$40000-400000$ & 0.0266 & 0.805 \\
\hline
\end{tabular}

Table 1: Constants $\mathrm{C}$ and $\mathrm{n}$ for use with equation(2.9)

indicated by the subscript $f$. The film temperature $T_{f}$, defined as the arithmetic mean between the eye surface(cornea or eyelid skin) and ambient air temperature

$$
T_{f}=\frac{T_{s}+T_{a}}{2}
$$

where $T_{s}$ is the eye surface temperature and $T_{a}$ air temperature. The parameter valuesk $k_{f}, v_{f}$ and $\operatorname{Pr}_{f}$ based on film temperature $T_{f}$ for air are tabulated in table 3 . We assume that all these parameter values are linearly dependent with film temperature $T_{f}$. The calculated convective heat transfer coefficient $h_{a}$ from equation (2.9) is substituted in boundary condition (2.3). 


\begin{tabular}{|c|c|c|c|}
\hline $\begin{array}{c}T_{f} \\
\left({ }^{\circ} \mathrm{C}\right)\end{array}$ & $\begin{array}{c}v_{f} \\
\left(\mathrm{~m}^{2} \mathrm{~s}^{-1}\right)\end{array}$ & $\begin{array}{c}k_{f} \\
\left(\mathrm{Wm}^{-1}{ }^{\circ} \mathrm{C}\right)\end{array}$ & $\operatorname{Pr}$ \\
\hline 27 & $15.69 \times 10^{-6}$ & 0.02624 & 0.708 \\
77 & $20.76 \times 10^{-6}$ & 0.03003 & 0.697 \\
\hline
\end{tabular}

Table 2: Properties of air[25]

\subsection{Methodology}

Effects of air flow in temperature distribution, specially, temperature drop in two wheeler riders eye surface is modeled using appropriate physical and physiological values at rider's different speed. For modeling purpose, we suppose that the effects of airflow in resting cornea is equivalent to the effects of still air in moving cornea. Based on this assumption the riders speed in still air is assumed as airflow speed. The two-wheeler rider's speed in valleys and hills is assumed $20 \mathrm{~km} / \mathrm{hr}$ as low, $40 \mathrm{~km} / \mathrm{hr}$ as normal and $60 \mathrm{~km} / \mathrm{hr}$ as high. The normal speed $40 \mathrm{~km} / \mathrm{hr}$ is the mean speed which the two-wheeler companies marked as most economy and efficient speed. Hence, to investigate the effects of air speed, the numerical calculations are carried out at speeds $0 \mathrm{~km} / \mathrm{hr}, 20 \mathrm{~km} / \mathrm{hr}, 40 \mathrm{~km} / \mathrm{hr}$ and $60 \mathrm{~km} / \mathrm{hr}$.

The governing equation (2.1) with boundary conditions (2.3) and (2.2) are solved using different parameter values. Two dimensional computations are carried out in steady and transient state cases. Transient thermal behavior of human eye is observed using Crank-Nicholson scheme for 1 hour. Eyelids are considered as a heating/cooling source of anterior cornea and model as a part of ocular component. In case of open eyelid, heat loss occurs from cornea and in closed eyelid, heat loss occurs from eyelid skin surface. Different parameter values for this loss are used in the analysis.

Blinking is the interrupted eyelid closure and opening. Beside various functions of eyelid blinking, heating and cooling mechanism play important role in maintaining anterior eye temperature. In transient analysis of blinking, the mesh size and the corresponding parameter values are continuously changed on each time step, this situation is modeled accordingly. At starting time $(t=0)$, the eyelids are supposed open and temperature values are calculated in open eye with eyelids. When eye blinks, eye mesh with closed lids are used to calculate temperature values. This mesh changing process continues until final time step.

\subsection{The control parameters}

Normal parameter values: ambient convection coefficient of $\operatorname{skin}\left(h_{s}\right)=6.28 \mathrm{Wm}^{-2^{\circ}} \mathrm{C}^{-1}$ [26], ambient convection coefficient of cornea $\left(h_{c}\right)=$

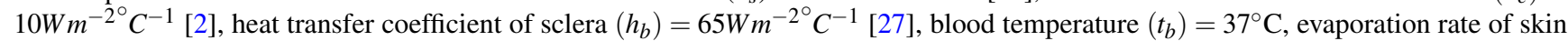
$E_{s}=96 \mathrm{~W} / \mathrm{m}^{2}$ [3], evaporation rate of cornea $E_{c}=40 \mathrm{~W} / \mathrm{m}^{2}$ [2]. The parameter values for different parts of eye are presented in table ??.

There are various biological and environmental factors that affect blinking rate. Some factors increase, while other decrease blinking

\begin{tabular}{|c|c|c|c|c|c|}
\hline $\begin{array}{l}\text { Tissue } \\
\text { Type }\end{array}$ & $\begin{array}{c}\text { Thermal } \\
\text { Conductivity } \\
K \\
\left(W m^{-1}{ }^{\circ} C^{-1}\right)\end{array}$ & $\begin{array}{c}\text { Blood } \\
\text { Perfusion } \\
\omega \\
\left(s^{-1}\right)\end{array}$ & $\begin{array}{c}\text { Metabolic } \\
\text { Rate } \\
Q_{m} \\
\left(W m^{-3}\right)\end{array}$ & $\begin{array}{c}\text { Density } \\
\rho \\
\left(K^{\prime} m^{-3}\right)\end{array}$ & $\begin{array}{c}\text { Specific } \\
\text { heat } \\
C \\
\left(J K g^{-1{ }^{\circ}} C^{-1}\right)\end{array}$ \\
\hline Dermis & $0.34[9]$ & $0.0087[9]$ & $1620[28]$ & $1070[9]$ & $3662[9]$ \\
\hline Orbicularis & $0.56[9]$ & $0.0034[9]$ & $480[28]$ & $1050[9]$ & 3639 [9] \\
\hline Tarsal & $0.47[28]$ & $0.0082[28]$ & $1600[28]$ & $1250[28]$ & $3600[28]$ \\
\hline Cornea & $0.58[13]$ & $0[9]$ & $0[28]$ & $1050[13]$ & $4178[13]$ \\
\hline Aqueous & $0.58[13]$ & $0[9]$ & $0[28]$ & $996[13]$ & 3997[13] \\
\hline Lens & $0.40[13]$ & $0[9]$ & $0[28]$ & $1050[13]$ & $3000[13]$ \\
\hline Vitreous & $0.603[13]$ & $0[9]$ & $0[28]$ & $1000[13]$ & $4178[13]$ \\
\hline Retina & $0.565[29]$ & $0.0222[9]$ & $22000[28]$ & $1050[29]$ & $3680[29]$ \\
\hline Iris & $0.52[28]$ & $0.01[28]$ & $10000[28]$ & $1050[28]$ & $3600[28]$ \\
\hline Ciliary & $0.498[29]$ & $0.008[29]$ & $6900[29]$ & $1050[29]$ & $3340[29]$ \\
\hline Sclera & $1.0042[13]$ & $0[29]$ & $0[29]$ & $1100[13]$ & $3180[13]$ \\
\hline
\end{tabular}

Table 3: Thermal properties of human eye tissues

rates. In normal condition, the average rate is lowest during high level of mental activity like reading and highest during conversation[30]. Generally, the time interval between two consecutive blink is $2-10$ seconds, actual rate varies by individual averaging around 10 blinks per minute in a laboratory setting [16]. In this study $10 \mathrm{blinks} / \mathrm{min}$ is taken as normal blink rate in still air and at normal ambient temperature. Based on many previous studies $[4,13,15], 20-25^{\circ} \mathrm{C}$ is assumed as normal air temperature and the temperature below and above this range is cold and hot. In this model, the normal ambient temperature is taken as $22.5^{\circ} \mathrm{C}$ (mean of the normal range $20-25^{\circ} \mathrm{C}$ ). To simulate airflow effects in cold and hot climatic conditions the corneal temperature values are calculated at $0^{\circ} \mathrm{C}, 10^{\circ} \mathrm{C}, 30^{\circ} \mathrm{C}$ and $40^{\circ} \mathrm{C}$ respectively.

For modeling purpose, we supposed that the effects of airflow in resting cornea is equivalent to the effects of still air in moving cornea. Based on this assumption the two wheeler riders speed in still air is assumed as airflow speed. Hence, to simulate the effects of wind speed and its effects, the numerical calculations are carried out at airflow speeds $0,20,40$ and $60 \mathrm{~km} / \mathrm{hr}$. The rider's speed $40 \mathrm{~km} / \mathrm{hr}$ is the mean speed which the two-wheeler companies marked as most economy and efficient speed, is assumed as normal speed.

Nakamori et al.[22] reported that high air velocity $(1.4 \mathrm{~m} / \mathrm{s})$ is associated with an increase (16.92.9 to 22.84.0) in blinking frequency in normal eyes. Koh et al.[21] reported that blink frequency increased significantly by $59 \%$ in dry eye patients after airflow exposure. We supposed that the blink frequency is increased by $50 \%$ in every increase of riders speed by $20 \mathrm{~km} / \mathrm{hr}$. Thus, the blink frequency of eyelid is taken as 10,15,22 and 33 blinks/min with inter-blink time interval of 5.5,3.6,2.32 and 1.41 seconds respectively at riders different speed. 
The oily layer of the pre-corneal tear film retards evaporation from the eye and if it destroyed, the rate may increase by a factor of fou $\mathrm{r}[31]$. The increased airflow into the corneal surface increases evaporation. Increased airflow also increases blinking rate. Increased blinking rate reduces eyelid opening time and with each blink a new lipid layer is spread across cornea that prevents evaporation. Hence evaporation is assumed as constant for different airflow speed. The corneal evaporation rate $40 \mathrm{Wm}^{-2}$ is used as normal rate at normal ambient temperature[13,15, 11]. Evaporation rate increases/decreases with increase/decrease in ambient temperature. In this study, corneal evaporation rates $0,15,40,100$ and $150 \mathrm{Wm}^{-2}$ are used for ambient temperatures $0,10,22.5,30$ and $40^{\circ} \mathrm{C}$ respectively. Similarly, skin evaporation rate at normal ambient temperature is $96 \mathrm{Wm}^{-2}$ [32]. Hence $0,20,96,140$ and $192 \mathrm{Wm}^{-2}$ are used for eyelid evaporation rate for ambient temperatures $0,10,22.5,30$ and $40^{\circ} \mathrm{C}$ respectively[20].

\section{Convergence study}

In this section we studied the convergence pattern of temperature values by varying the mesh size in open eye without eyelids. At first, initial triangular mesh of size 552 elements (coarse mesh) are constructed and temperature values are obtained as shown in figure 3.1. Next we subdivide each triangle into four sub-triangles by joining the mid point of each sides of that triangle. The corresponding mesh of size 2208 elements (normal mesh) and its temperature distribution are shown in figure 3.2. The triangular mesh is again further subdivided to get fine and extremely fine mesh of size 8832 and 35328 elements as shown in figures 3.3 and 3.4 respectively. The temperature values of cornea are tabulated in table 4.

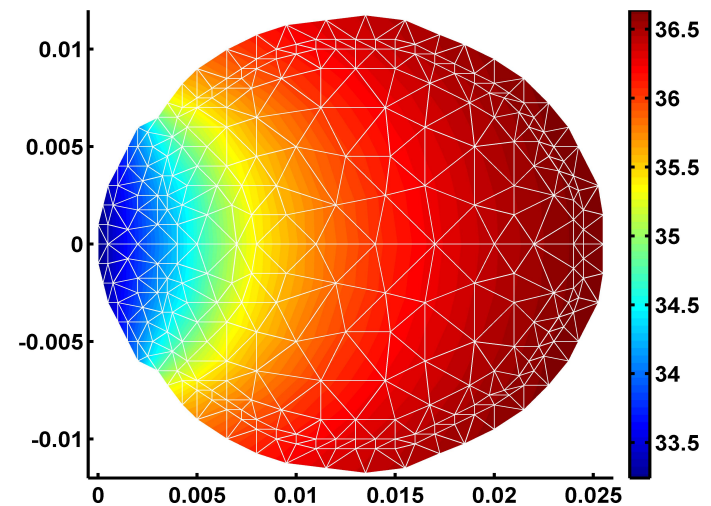

Figure 3.1: Temperature distribution of human eye tissues at triangular mesh of size 552 elements.

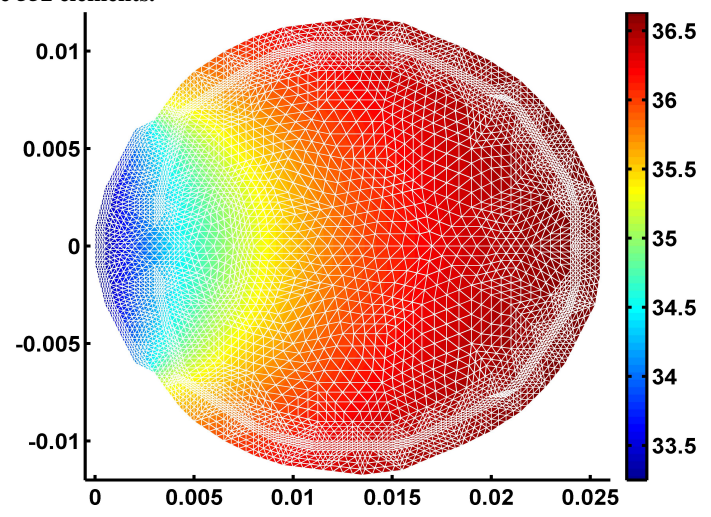

Figure 3.3: Temperature distribution of human eye tissues at triangular mesh of size 8832 elements.

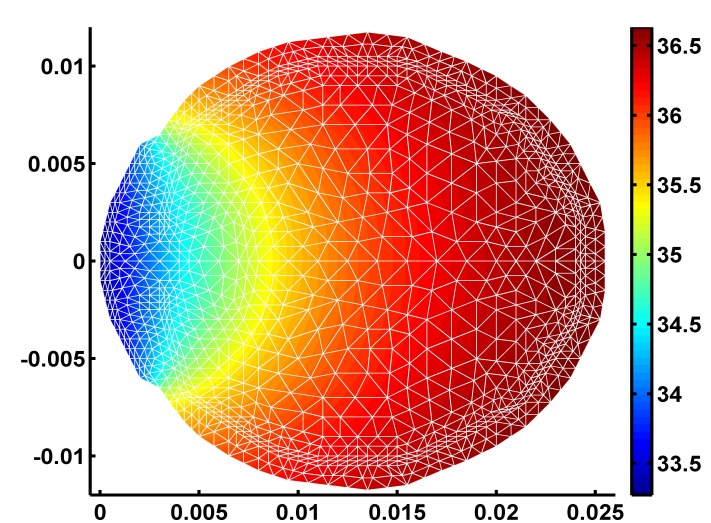

Figure 3.2: Temperature distribution of human eye tissues at triangular mesh of size 2208 elements.

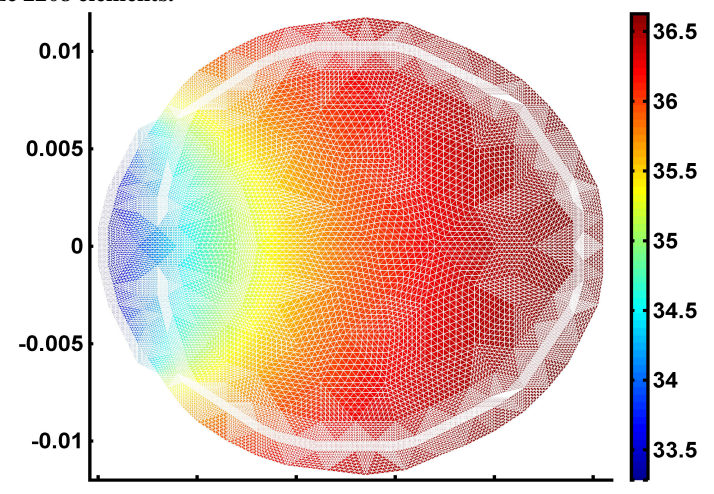

Figure 3.4: Temperature distribution of human eye tissues at triangular mesh of size 35328 elements.

\begin{tabular}{|c|c|c|}
\hline Mesh type & Mesh size & Temperature values \\
\hline Coarse & 552 & $33.21^{\circ} \mathrm{C}$ \\
Normal & 2208 & $33.23^{\circ} \mathrm{C}$ \\
Fine & 8832 & $33.25^{\circ} \mathrm{C}$ \\
Extremely fine & 35328 & $33.26^{\circ} \mathrm{C}$ \\
\hline
\end{tabular}

Table 4: Convergence study in Two dimensional temperature variation of cornea

\section{Results}

The temperature distribution of human eye in case of eyelid opening and closure at ambient temperature $22.5^{\circ} \mathrm{C}$ and at air flow rates $20 \mathrm{~km} / \mathrm{hr}$, $40 \mathrm{~km} / \mathrm{hr}$ and $60 \mathrm{~km} / \mathrm{hr}$ are shown in 4.1 .

The transient temperature distributions are calculated at different air temperatures $0,10,22.5,30$ and $40^{\circ} \mathrm{C}$ and air speeds $0 \mathrm{~km} / \mathrm{hr}, 20 \mathrm{~km} / \mathrm{hr}, 40 \mathrm{~km} / \mathrm{hr}$ 

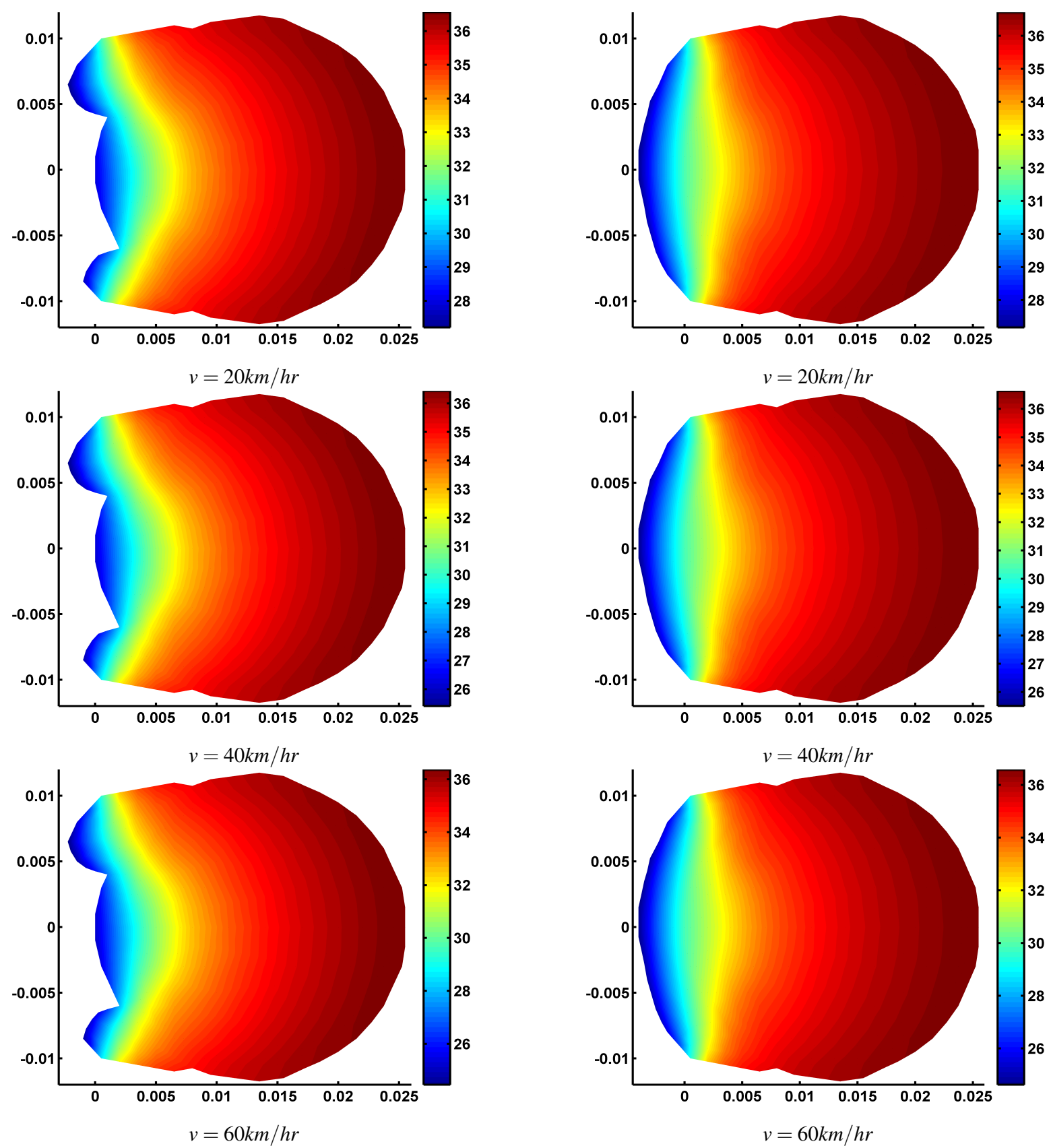

Figure 4.1: Influence of different air speeds and eyelid positions (opened and closed) temperature distribution at ambient temperature $T_{a}=22.5^{\circ} \mathrm{C}$.

and $60 \mathrm{~km} / \mathrm{hr}$ as discussed above. The transient thermal behavior of human eye is observed for 1 hour using 1 -second time step size. The temperature values for eyelid opening, eyelid closure and different blinking rates 10,15,22 and 33 blinks/min at ambient temperature $22.5^{\circ} \mathrm{C}$ and in still air is presented in figure 4.2.

Figure 4.2 shows that the corneal surface temperature values obtained are $30.36,32.73,33.10,33.47,33.84$ and $35.58^{\circ} \mathrm{C}$ at eyelid opening, $10 \mathrm{blinks} / \mathrm{min}, 15 \mathrm{blink} / \mathrm{min}, 22 \mathrm{blink} / \mathrm{min}, 33 \mathrm{blink} / \mathrm{min}$ and eyelid closure respectively. The steady state corneal temperature is observed in around 41 and 25 minutes during eyelid opening and closure respectively. When blinking rate increases from 10 to 33 the steady state temperature is observed in around 38,35,33 and 30 minutes respectively. However, in figure4.2, the actual blinking pattern is unable to see because blinking time (eyelid closure time) and inter-blink interval is very short. Hence to show the blinking pattern, the further graphs are plotted by showing only one blinking pattern in a minute.

In figure 4.3, we observed the temperature distribution of cornea at different blinking rates and air speeds at $0^{\circ} \mathrm{C}$ ambient temperature. The corneal temperature is dropped by $11.54,16.88$ and $17.46^{\circ} \mathrm{C}$ during closure, blinking and opening respectively.

Figure 4.4 shows the corneal temperature distribution at different airflow speeds and at different blinking rates at ambient temperature $10^{\circ} \mathrm{C}$. The corneal temperature observed is $34.95,29.34,27.64$ and $26.68^{\circ} \mathrm{C}$ during eyelid closure, $30.61,20.90,19.10$ and $18.52^{\circ} \mathrm{C}$ during blinking and $26.22,16.77,14.84$ and $13.93^{\circ} \mathrm{C}$ during eyelid opening respectively.

The corneal temperature at $22.5^{\circ} \mathrm{C}$ temperature and at different blinking rates and air speeds is shown in figure 4.5. The temperature decreases from $30.36^{\circ} \mathrm{C}$ to $24.50^{\circ} \mathrm{C}, 33.10^{\circ} \mathrm{C}$ to $26.97^{\circ} \mathrm{C}$ and $35.58^{\circ} \mathrm{C}$ to $31.34^{\circ} \mathrm{C}$ at eyelid opening, blinking and closure respectively.

In figure 4.6, we observed the temperature distribution of cornea at different blinking rates and air speeds at $30^{\circ} \mathrm{C}$ ambient temperature. The corneal temperature is dropped by $1.84,2.57$ and $2.02^{\circ} \mathrm{C}$ during closure, blinking and opening respectively. 


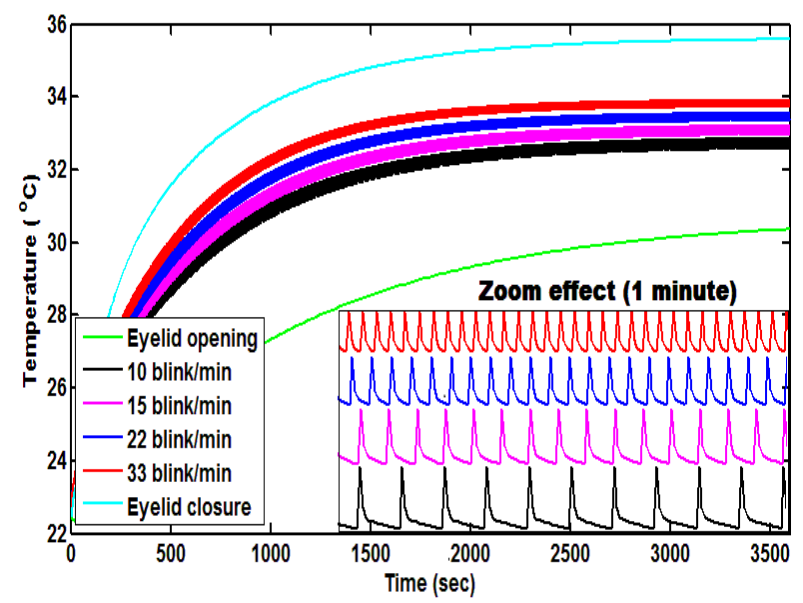

Figure 4.2: Temperature values for different blinking rates
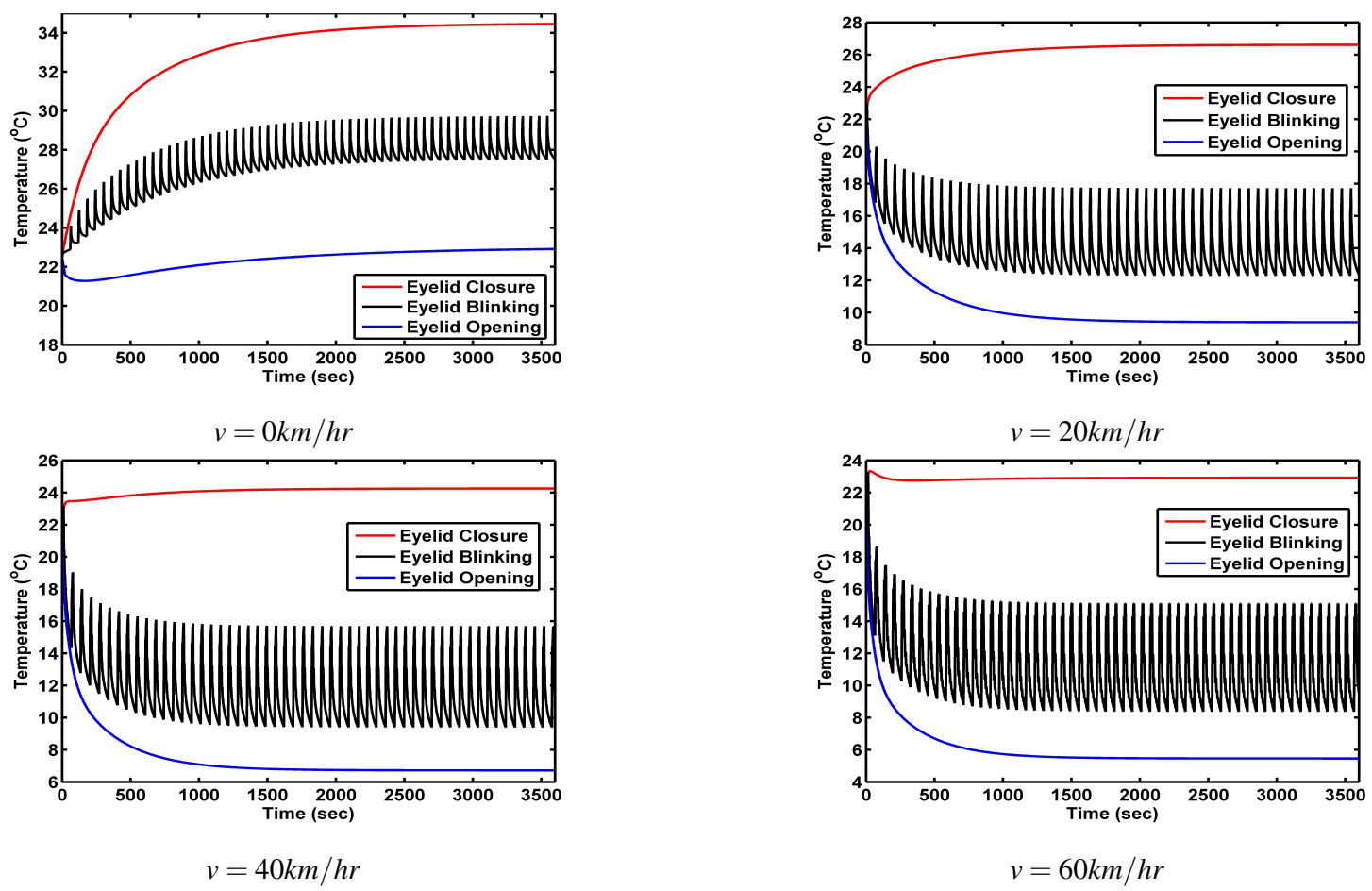

Figure 4.3: Corneal temperatures at ambient temperature $0^{\circ} \mathrm{C}$

Figure 4.7 shows the corneal temperature at different air speeds and blinking rates and at $40^{\circ} \mathrm{C}$ ambient temperature. The corneal temperature is dropped by $0.36,1.31,1.4^{\circ} \mathrm{C}$ and $1.42^{\circ} \mathrm{C}$ at $0,20,40$ and $60 \mathrm{~km} / \mathrm{hr}$ air speeds respectively.

\section{Discussion}

The corneal temperature is highest in eyelid closure, lowest in eyelid opening and in between these two values during blinking when ambient temperature is less than physiological temperature of body $\left(37^{\circ} \mathrm{C}\right)$ and vice versa. In eyelid closure heat is conducted/convected from vascular eyelid to avascular cornea, since the perfused blood flow in eyelid has temperature approaching to body core. If eye surface temperature drops or rises beyond normal level then heat is convected in or out via blood flow through eyelid.

When blinking rate increases 1) eyelid closure time increases 2) secretion and spread of tear layer across cornea increases and 3) uniform distribution and thickness of lipid layer increases. Uniform distribution and thick lipid layer across cornea prevents evaporation of tear from cornea. Closure of eyelid prevents convection, radiation and tear evaporation from cornea. Hence, all these factors increase corneal temperature for ambient temperature less than $37^{\circ} \mathrm{C}$ and vice versa.

Rapid decrease in corneal temperature is observed at low atmospheric temperatures. The decreasing rate is highest in eyelid opening than blinking and lowest in closure. High amount of heat is lost to environment via convection and radiation in low ambient temperature. In open eye heat conducted from eye core to cornea is insufficient to maintain corneal temperature in normal level. Increased blinking rate may help to increase corneal temperature at low ambient temperature conditions. In our case at ambient temperature $0^{\circ} \mathrm{C}$, blinking increases eye temperature by $5.40^{\circ} \mathrm{C}, 5.64^{\circ} \mathrm{C}, 5.82^{\circ} \mathrm{C}$ and $6.28^{\circ} \mathrm{C}$ at air speeds $0 \mathrm{~km} / \mathrm{hr}, 20 \mathrm{~km} / \mathrm{hr}, 40 \mathrm{~km} / \mathrm{hr}$ and $60 \mathrm{~km} / \mathrm{hr}$ respectively. Similarly at ambient temperature $40^{\circ} \mathrm{C}$, blinking decreases eye temperature by $0.27^{\circ} \mathrm{C}, 0.42^{\circ} \mathrm{C}, 0.46^{\circ} \mathrm{C}$ and $0.51^{\circ} \mathrm{C}$ at air speeds $0 \mathrm{~km} / \mathrm{hr}, 20 \mathrm{~km} / \mathrm{hr}$, 

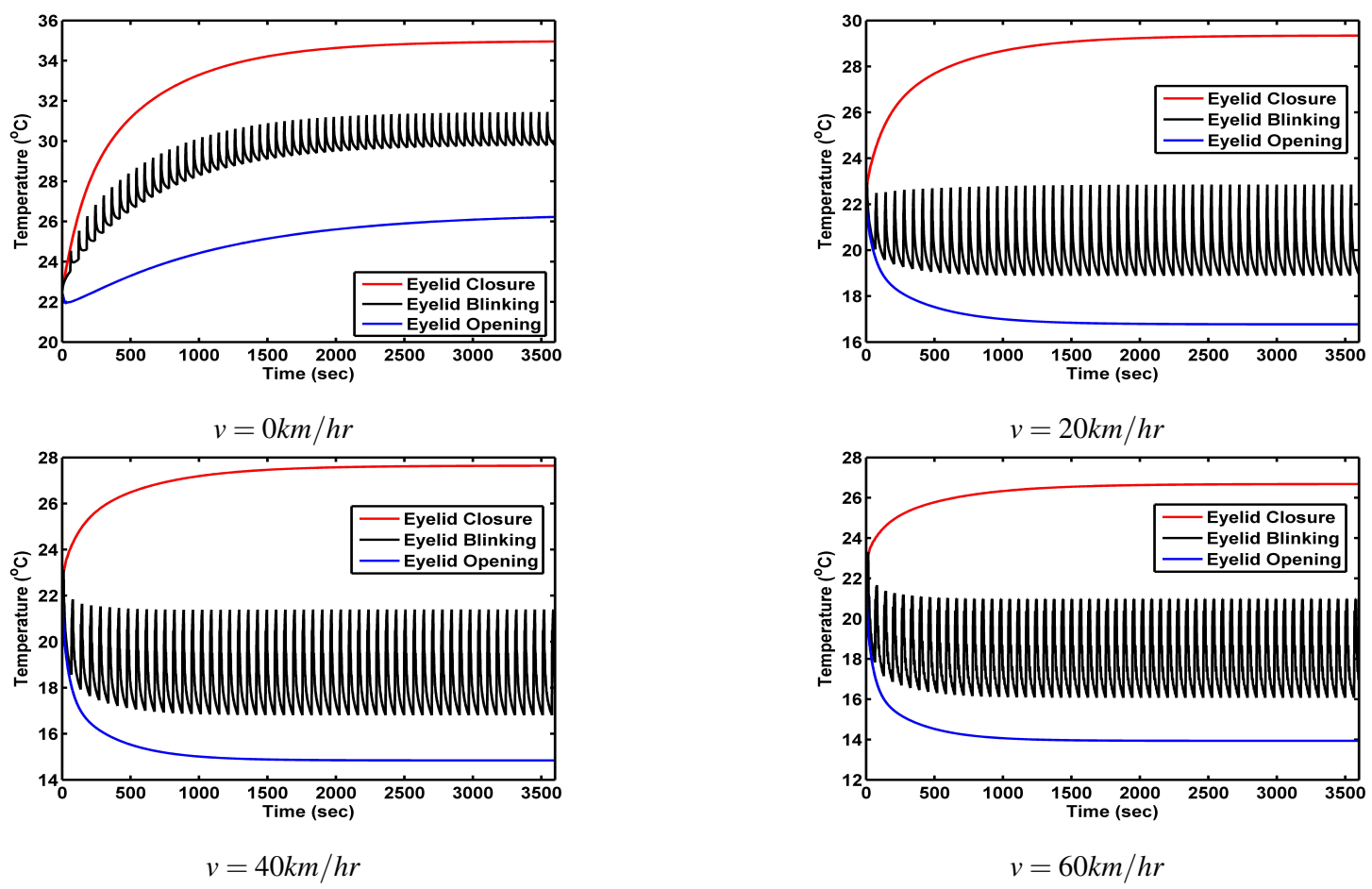

Figure 4.4: Corneal temperatures at ambient temperature $10^{\circ} \mathrm{C}$
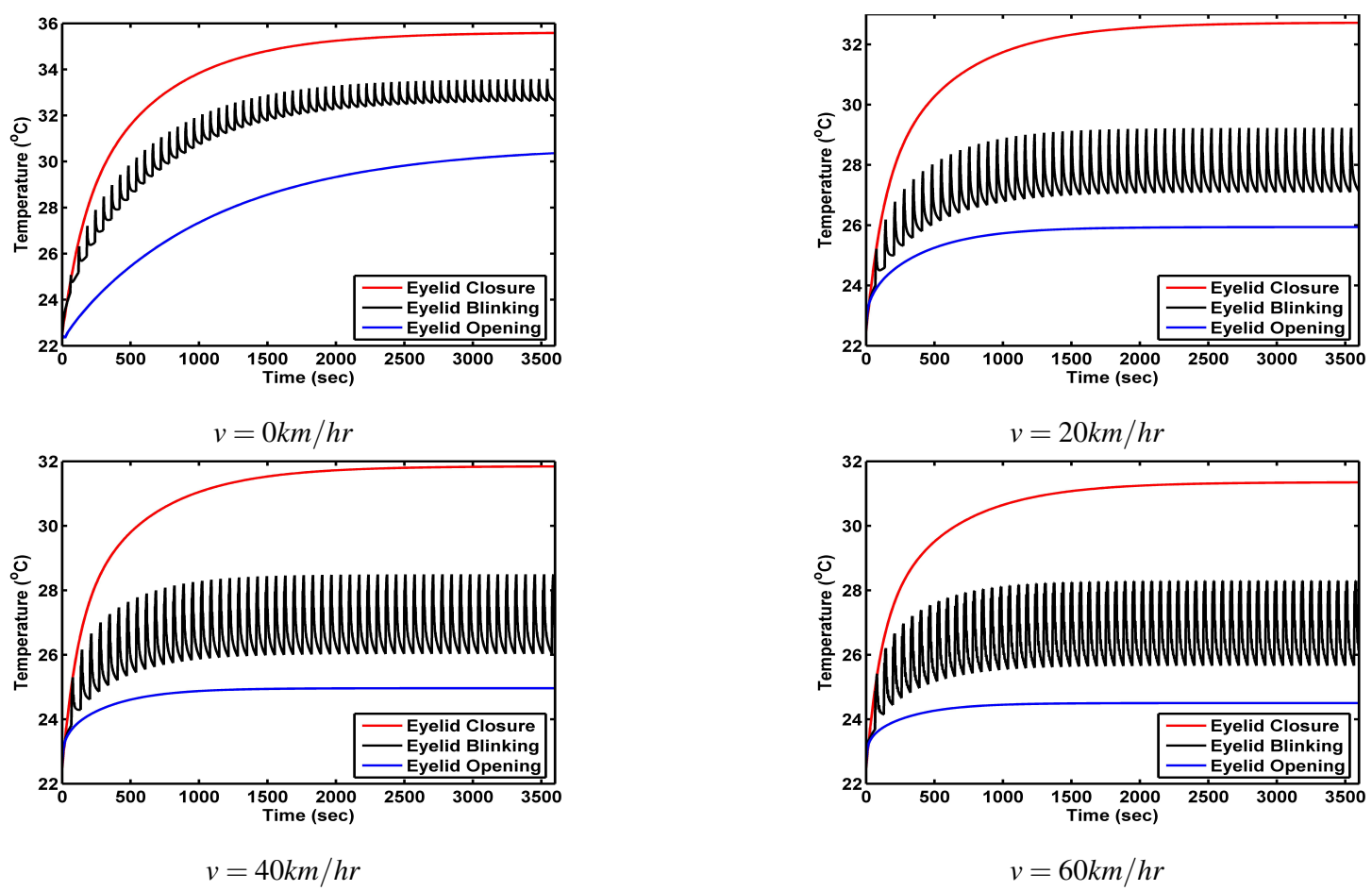

Figure 4.5: Corneal temperatures at ambient temperature $22.5^{\circ} \mathrm{C}$

$40 \mathrm{~km} / \mathrm{hr}$ and $60 \mathrm{~km} / \mathrm{hr}$ respectively.

Increase in ambient air speed decreases corneal temperature. The rapid decrease of corneal surface temperature is observed at high air speeds. With increase in air speed, more air molecules hit the corneal surface, which may increase the rate of evaporation of water molecules from cornea. In cold temperatures and in still air the difference in temperature between air molecules and corneal surface is very high $\left(22.91{ }^{\circ} \mathrm{C}\right.$, $28.61^{\circ} \mathrm{C}$ and $34.45^{\circ} \mathrm{C}$ in open, blinking and closed eye respectively at $0^{\circ} \mathrm{C}$ ambient temperature). This obviously increases heat transfer. However, the cornea is continuously heated by conduction from body core to maintain steady temperature in open eye.

In addition, cornea is heated by warm conjunctiva of eyelid and tearing in eyelid closure. On the other hand, in still air there is a thick thermal boundary layer at the surface of cornea. The increase in air speed plays a role of catalyst in heat transfer, which makes thinner the boundary layer and decreases the diffusion distance. This phenomenon increases heat transfer between ambient air and cornea in eyelid opening and skin surface in eyelid closure. But in hot temperature the difference is very small $\left(3.18^{\circ} \mathrm{C}, 3.45^{\circ} \mathrm{C}\right.$ and $3.54^{\circ} \mathrm{C}$ in open , blinking 

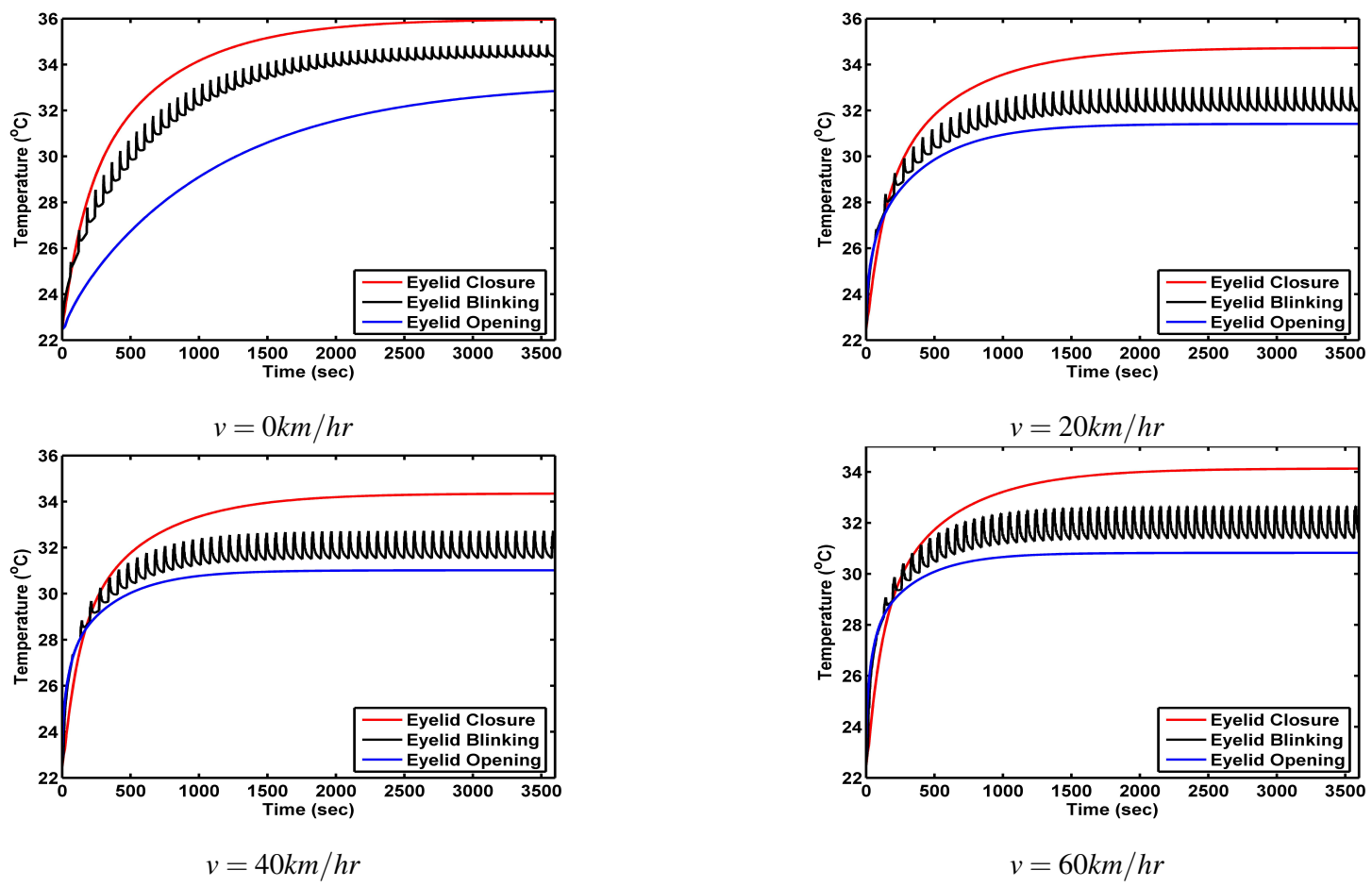

Figure 4.6: Corneal temperatures at ambient temperature $30^{\circ} \mathrm{C}$
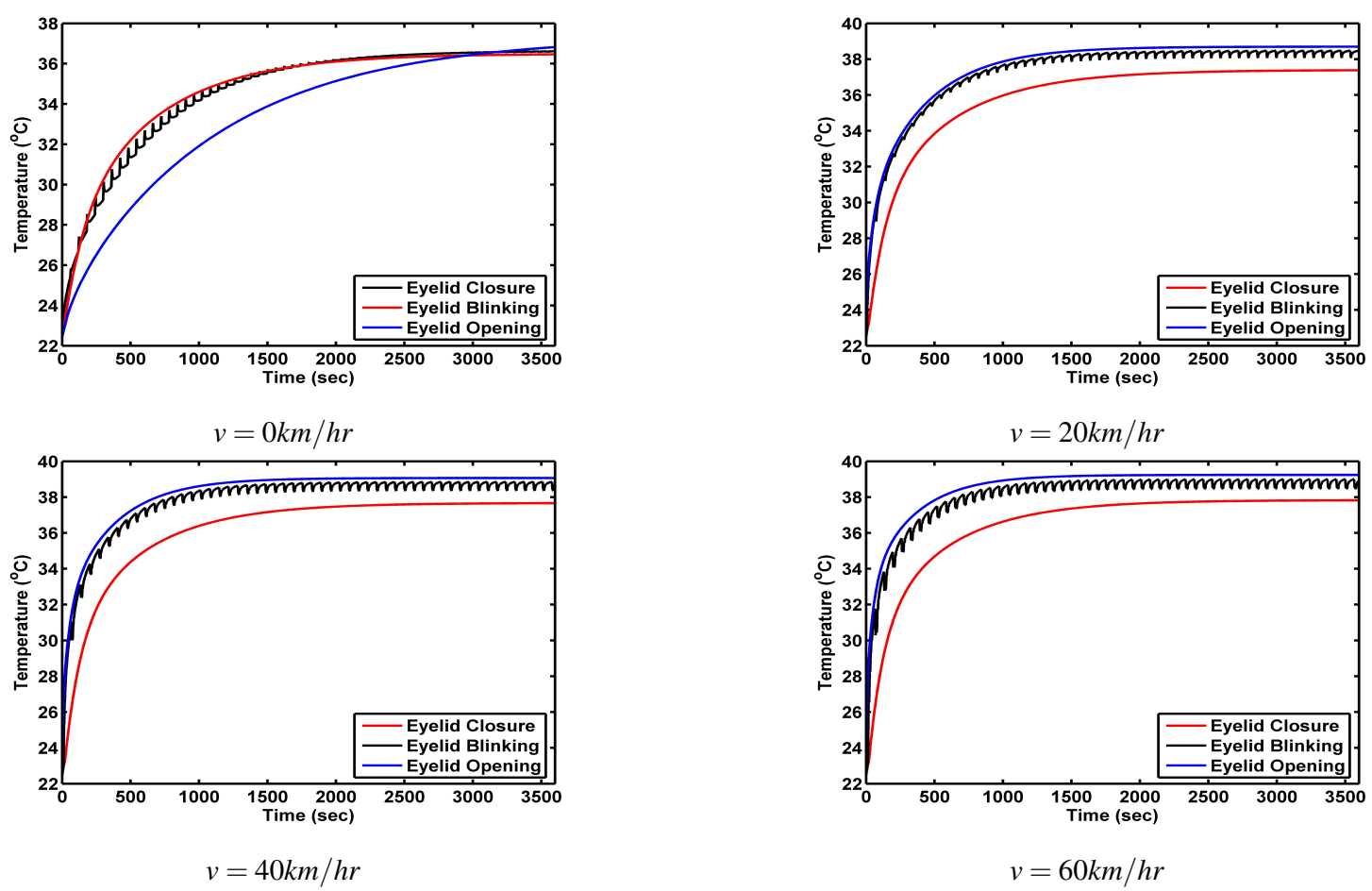

Figure 4.7: Corneal temperatures at ambient temperature $40^{\circ} \mathrm{C}$

and closed eye respectively at $40^{\circ} \mathrm{C}$ air temperature). Although heat transfer increases with increase in air speed the corneal temperature is not significantly affected by air speeds in hot climatic conditions due to this small temperature difference.

The outermost layer of the cornea (meibomian lipid layer) solidifies below $19^{\circ} \mathrm{C}$, quasi solid in the range between $20-30^{\circ} \mathrm{C}$ and completely clear liquid in the range between $30-45^{\circ} \mathrm{C}$ [19]. Thus, if the corneal surface temperature drops below $30^{\circ} \mathrm{C}$, the meibomian layer may become thicker and solid than usual, this can lead blurred vision. In our case, in still air and at $0^{\circ} \mathrm{C}$ ambient temperature, corneal temperature is found as $22.91^{\circ} \mathrm{C}, 28.61^{\circ} \mathrm{C}$ and $34.45^{\circ} \mathrm{C}$ in eyelid opening, blinking and closure respectively. Similarly at air speed $60 \mathrm{~km} / \mathrm{hr}$ and ambient temperature $0^{\circ} \mathrm{C}$ the corneal surface temperature drops to $5.45^{\circ} \mathrm{C}, 11.73^{\circ} \mathrm{C}$ and $22.91^{\circ} \mathrm{C}$ in eyelid opening, blinking and closure respectively. This may solidify the meibomian lipid layer, which may cause blurred vision. In addition, high air speed affects the distribution of tear film and lipid layer which protects the corneal epithelium against the evaporation of aqueous tears [33]. High air velocity causes greater evaporation of water from the pre-corneal tear film. Exposure of tear film to high air velocity caused significant decrease in lipid layer 
stability, tear stability and tear meniscus [21]. If the lipid layer destroyed, the evaporation from the tear film increases approximately 4 times greater than with the lipid layer [31]. This higher rate of evaporation reduces corneal temperature rapidly.

The steady state temperature is achieved earlier in higher air speeds. The corneal temperature reaches in steady state very fast at air speed $60 \mathrm{~km} / \mathrm{hr}$ (approximately 9 minutes, 13 minutes and 20 minutes in open, blinking, and closed eye respectively) than in still air (approximately 25 minutes, 35 minutes and 41 minutes in closed, blinking and open eye respectively). In cold temperatures, the steady state temperature drops very well and plateau of corneal temperature is achieved faster in higher air speeds. In hot climatic conditions the steady state temperature of cornea does not drop significantly but plateau of corneal temperature is achieved faster as in cold climatic conditions.

The flow speed equally affects the thermal boundary layer (reducing the thickness) either in hot or cold conditions. This causes increase in heat transfer approximately at the same manner in both hot and cold climatic conditions. The value of heat transfer coefficient at air speed $60 \mathrm{~km} / \mathrm{hr}$ is found as $122.80 \mathrm{Wm}^{-2}{ }^{\circ} \mathrm{C}^{-1}$ and $119.30 \mathrm{Wm}^{-2}{ }^{\circ} \mathrm{C}^{-1}$ at ambient temperatures $0^{\circ} \mathrm{C}$ and $40^{\circ} \mathrm{C}$ respectively.

\section{Validation studies}

Gurung and Saxena [20] studied the effects of air flow in human skin temperature. They found a drop in human skin temperature of $7.45^{\circ} \mathrm{C}$ at $0^{\circ} \mathrm{C}$ atmospheric temperature and at $4 \mathrm{~m} / \mathrm{s}$ air speed. Our result at atmospheric temperature $0^{\circ} \mathrm{C}$ and air speed $5 \mathrm{~m} / \mathrm{s}$ shows a higher temperature value $15.03^{\circ} \mathrm{C}$ on eyelid skin surface. They modeled skin including subcutaneous tissue with increasing blood perfusion from $2 \mathrm{~mm}$ deep to body core. In our case only $0.6 \mathrm{~mm}$ of eyelid outer surface having no blood perfusion. Also concentration of blood vessels in eyelid is higher than in normal skin. In such cases our results may valid compare to the results from Gurung and Saxena.

Freeman and Fatt [34] studied the effects of air velocity on human cornea temperature experimentally using thermistor probe and Thermometer Bridge. They observed $13^{\circ} \mathrm{C}$ temperature drop at $4 \mathrm{~m} / \mathrm{s}$ air velocity and at $0^{\circ} \mathrm{C}$ ambient temperature. In our case, the corneal surface temperature is obtained to be $9.39^{\circ} \mathrm{C}$ at $5 \mathrm{~m} / \mathrm{s}$ air speed and at $0^{\circ} \mathrm{C}$ ambient temperature. This shows that our modeling results are valid with Freeman and Fatt's experimental results.

\section{Conclusion}

We have presented finite element model of human eye and computed its steady and transient state temperature distribution during eyelid opening, closure and blinking. The airflow forced convection effects on temperature distribution of cornea is simulated. The study focused on the change in temperature of two wheeler rider's cornea in hot and cold climatic conditions at different air speeds. Increased blinking rate is found to increase corneal temperature significantly. In our case anterior corneal temperature is increased by $2.74{ }^{\circ} \mathrm{C}$ while blinking than in open eye at normal ambient temperature and in still air.

The temperature difference at cornea during eyelid opening, blinking and closure increases as ambient temperature decreases and vice versa. Similarly the difference increases as air speed increases. Corneal temperature plateaus very fast in high air speed than in still air in all climatic conditions. High air speed in cold ambient temperature is hazardous for ocular surface. In this situation, thermal feedback mechanism would require to increase local temperature. Long time exposure of cornea to cold weather and in high air speed may reduce refractive outcomes and increase the risk of dry eye.

\section{References}

[1] K. R. Bhatnagar, A. Sapovadia, D. Gupta, P. Kumar, H. Jasani, Dry eye syndrome: A rising occupational hazard in tropical countries, Medical J. Dr. D. Y. Patil Uni., 7 (2014), 13-18.

[2] K. C. Gokul, D. B. Gurung, P. R. Adhikary, Transient thermal model of airflow effects in human eye temperature, Kathmandu Uni. J. Uni. Sci. Eng. Tech., 9 (2013), 47-58.

[3] K. C. Gokul, D. B. Gurung, P. R. Adhikary, Modeling airflow effects in human eye temperature with and without eyelids, Int. J. Appl. Math. Mech., 10 (2014), 82-98.

[4] J. A. Scott, The computation of temperature rises in the human eye induced by infrared radiation, Phys. Med. Biol., 33 (1988), $243-257$.

[5] R. Mapstone, Determinants of corneal temperature, British J. Ophthalmology, 52 (1968), 729-741.

[6] D. H. Sliney, Physical factors in cataractogenesis: Ambient ultraviolet radiation and temperature, Investigative Ophthalmology Vis. Sci., 27 (1986), 781-790.

[7] H. Fujishima, I. Toda, M. Yamada, N. Sato, K. Tsubota, Corneal temperature in patients with dry eye evaluated by infrared radiation thermometry, British J. Ophthalmology, 80 (1996), 29-32.

[8] J. J. Lagendijk, A mathematical model to calculate temperature distributions in human and rabbit eyes during hyperthermia treatment, Phys. Med. Biol., 27 (1982), 1301-1311.

[9] V. M. M. Flycket, B. W. Roaymakers, J. J. W. Lagendijk, Modeling the impact of blood flow on the temperature distribution in the human eye and the orbit: fixed heat transfer coefficient versus the pennes bioheat model versus discrete blood vessels, Phys. Med. Biol., 51 (2006), 5007-5021.

[10] J. A. Scott, A finite element model of heat transport in the human eye, 51(33) (1988), 227-241.

[11] M. Shafahi, K. Vafai, Human eye response to thermal disturbances, J. Heat Transfer, 133 (2011), Article ID 011009.

[12] N. Sharon, P. Z. B. Yoseph, B. Bormusov, A. Dovrat, Simulation of heat exposure and damage to the eye lens in a neighborhood bakery, Experiment. Eye Res., 87 (2008), 49-55.

[13] E. Y. K. Ng, E. H. Ooi, Fem simulation of the eye structure with bio-heat analysis, Comput. Methods Programs Biomedicine, 82 (2006), $268-276$.

[14] E. H. Ooi, E. Y. K. Ng, Simulation of aqueous humor hydrodynamics in human eye heat transfer, Computer. Biol. Med., 38 (2007), $252-262$.

[15] K. C. Gokul, D. B. Gurung, P. R. Adhikary, Effects of blood perfusion and metabolism in temperature distribution in human eye, Adv. Appl. Math. Biosci., 4 (2013), 13-23.

[16] S. A. Schellini, A. A. Sampaio, E. Hoyama, A. A. V. Cruz, C. R. Padovani, Spontaneous eye blink analysis in the normal individual, Orbit, 24 (2005), $239-242$.

[17] D. B. Gurung, K. C. Gokul, Mathematical model of thermal effects of blinking in human eye, Int. J. Biomath., 9 (2016), 1650006.

[18] L. Kessel, L. Johnson, H. Aridsson, M. Larsen, The relationship between body and ambient temperature and corneal temperature, Investigative Ophthalmology Vis. Sci., 51 (2010), 6593-6597.

[19] I. A. Butovich, J. C. Arciniega, J. C. Wojtowicz, Meibomian lipid films and the impact of temperature, Investigative Ophthalmology Vis. Sci., 51 (2010), 5508-5518.

[20] D. B. Gurung, V. P. Saxena, Pheripheral temperature distribution in human subjects exposed to wind flow, Int. J. Math. Engrg., 2 (2010), $728-740$.

[21] S. Koh, C. Tung, R. Kottaiyan, J. Zavislam, G. Yoon, J. Aquavella, Effect of airlfow exposure on the tear mensiscus, J. Ophthalmology, (2012), Article

[22] K. Nakamori, M. Odawara, T. Nakajima, T. Mizutani, K. Tsubota, Blinking is controlled primarily by ocular surface conditions, Amer. J. Ophthalmology 124 (1997), 23-30.

[23] H. H. Pennes, Analysis of tissue and arterial blood temperatures in the resting human forearm, J. Appl. Physiology, 85 (1998), 5-34. 
[24] R. J. Dear, E. Arens, Z. Hui, Convective and radiative heat transfer coefficients for individual human body segments, Int. J. Biometeorol, 40 (1997),

[25] J. P. Holman, Heat Transfer, eighth si metric ed., Mc Graw Hill, India, 2001.

[26] K. C. Gokul, D. B. Gurung, P. R. Adhikary, Thermal effects of eyelid in human eye tempearture, J. Appl. Math. Inform., 32 (2014), 649-663.

[27] K. C. Gokul, D. B. Gurung, Mathematical model: Comparative study of thermal effects of laser in corneal refractive surgeries, Appl. Appl. Math., 10 (2015), 609-619.

[28] A. Hirata, S. Watanabe, O. Fujiwara, M. Kojima, K. Sasaki, T. Shiozawa, Temperature elevation in the eye of anatomically based human head models for plane-wave exposures, Phys. Med. Biol., 52 (2007), 6389-6399.

[29] M. Cvetkovic, D. Poljak, A. Peratta, Fetd computation of the temperature distribution induced into a human eye by a pulsed laser, Prog. Electromagn., 120 (2011), 403-421.

[30] J. Kaminer, A. S. Powers, K. G. Horn, C. Hui, C. Evinger, Characterizing the spontaneous blink generator: An animal model, J. Neurosci., 31 (2011), $11256-11267$.

[31] S. Iwata, M. A. Lemp, F. J. Holly, C. H. Dohlman, Evaporation rate of water from the precorneal tear film and cornea in the rabbit, Investigative Ophthalmology Vis. Sci., 8 (1969), 613-619.

[32] S. Acharya, D. B. Gurung, V. P. Saxena, Effect of metabolic reactions on thermoregulation in human males and females body, Appl. Math., 4 (2013),

[33] A. H. Rantamaki, M. Javanainen, I. Vattulainen, J. H. Holopainen, Do lipids retard the evaporation of the tear fluid?, Investigative Ophthalmology Vis. Sci., 53 (2012), 6442-6447.

[34] R. D. Freeman, I. Fatt, Environmental influences on ocular temperature, Investigative Ophthalmology Vis. Sci., 12 (1973), $596-602$. 